\title{
Diversity of Cryptosporidium species occurring in sheep and goat breeds reared in Poland
}

\author{
Agnieszka Kaupke $^{1}$ - Mirosław M. Michalski ${ }^{2}$ - Artur Rzeżutka ${ }^{1}$
}

Received: 8 November 2016 / Accepted: 20 December 2016/Published online: 5 January 2017

(C) The Author(s) 2017. This article is published with open access at Springerlink.com

\begin{abstract}
The aim of this study was molecular identification of Cryptosporidium species and assessment of their prevalence in different breeds of sheep and goat reared in Poland. In addition, the relationship between animal age, breed type, and the frequency of Cryptosporidium infections was determined. Fecal samples from 234 lambs and 105 goat kids aged up to 9 weeks, representing 24 breeds and their cross-breeds were collected from 71 small ruminant farms across Poland. The identification of Cryptosporidium species was performed at the $18 \mathrm{SSU}$ ribosomal RNA (rRNA) and COWP loci followed by subtyping of $C$. parvum and C. hominis strains at GP60 gene locus. The presence of Cryptosporidium DNA at the $18 \mathrm{SSU}$ rRNA locus was detected in 45/234 (19.2\%) lamb feces samples and in 39/105 (37.1\%) taken from goats. The following Cryptosporidium species: C. xiaoi, C. bovis, C. ubiquitum, C. parvum, and C. hominis were detected in small ruminants. Infections caused by C. xiaoi were predominant without favoring any tested animal species. Subsequent GP60 subtyping revealed the presence of $C$. parvum IIaA17G1R1 subtype in sheep and IIdA23G1 subtype in goats. IIdA23G1 subtype was detected in a goat host for the first time. There were no significant differences found in frequency of infections between the age groups $(<3$ and $3-$ 9 weeks $)$ of lambs $(P=0.14, \alpha>0.05)$ or goat kids
\end{abstract}

Artur Rzeżutka

arzez@piwet.pulawy.pl

1 Department of Food and Environmental Virology, National Veterinary Research Institute, al. Partyzantów 57, 24-100 Puławy, Poland

2 Department of Parasitology and Invasive Diseases, Faculty of Veterinary Medicine, University of Warmia and Mazury, Oczapowskiego 13, 10-719 Olsztyn, Poland
$(P=0.06, \alpha>0.05)$. In addition, there was no correlation observed between the frequency in occurrence of particular parasite species and breed type in relation to native sheep breeds $(F=0.11 ; P=0.990>0.05)$. In the case of goats, more breed-related differences in parasite occurrence were found. The results of this study improve our knowledge on the breedrelated occurrence of Cryptosporidium infections in the population of small ruminants reared in Poland.

Keywords Cryptosporidium · Prevalence · Sheep · Goat · Breed

\section{Introduction}

Cryptosporidiosis has been described in a variety of farm animals including sheep and goats. Some data exists on the Cryptosporidium species/genotypes infecting small ruminants reared all over the world (Karanis et al. 2007; Mueller-Doblies et al. 2008; Pritchard et al. 2008; Quílez et al. 2008; Paoletti et al. 2009; Robertson et al. 2010; Díaz et al. 2010; Imre et al. 2013; Connelly et al. 2013; Rieux et al. 2013; Tzanidakis et al. 2014; Yang et al. 2014; Díaz et al. 2015). It reveals the prevalence of C. ubiquitum, C.xiaoi, and C. parvum to be the highest in these animal hosts. However, depending on the geographical region, other Cryptosporidium species such as C. andersoni (sheep and goats), C. hominis (goats), C. bovis (sheep), and occasionally C. scrofarum and C. suis may also be isolated (Koinari et al. 2014; Yang et al. 2014). Small ruminants are also known as a reservoir of $C$. hominis (Ryan et al. 2005; Giles et al. 2009; Connelly et al. 2013; Kang'ethe et al. 2012; Koinari et al. 2014) and zoonotic C. parvum for humans (Geurden et al. 2008; Quílez et al. 2008; Paoletti et al. 2009; Robertson 2009; Imre et al. 2013; Cacciò et al. 2013; Lange et al. 2014; Díaz et al. 2015; Taylan-Ozkan et al. 2016). 
Although infections are frequently reported, their impact on animal health seems to be of less importance than in cattle. Usually, Cryptosporidium infections in small ruminants are asymptomatic and are only rarely accompanied by gastrointestinal disorders. The symptomatic course of Cryptosporidium infection is characterized by neonatal diarrheal diseases which are associated with $C$. parvum and sporadically with C. ubiquitum or C. xiaoi infections (Imre et al. 2013).

The significant economic losses in sheep and goat breeding attributed to parasitic infections are due to invasion of coccidia (Vasilkova et al. 2004; Balicka-Ramisz et al. 2012), sheep tapeworm (Moniezia spp.), and nematodes from the Trichostrongylidae family (Malczewski 1970; Buddle et al. 1988). However, the main causes of morbidity and mortality among small ruminants are bacterial or viral infections complicated by parasites including Cryptosporidium (Mason et al. 1981; Ozmen et al. 2006). Although several studies aimed at detecting and identifying Cryptosporidium in farm animals have been conducted, our knowledge of parasite occurrence and worldwide distribution in animals is still not complete (Plutzer and Karanis 2009; Xiao 2010). For example, studies concerning cryptosporidiosis in small ruminants were mostly focused on parasite detection using microscopic methods without subsequent identification of parasite species. Therefore, little is known about the epidemiology of Cryptosporidium infections caused by particular parasite species and their occurrence in the population of small ruminants in Eastern European countries. Data is also lacking on transmission dynamics within animal population, age, or breedrelated parasite occurrence (Díaz et al. 2015).

Currently, sheep farming in Poland is not pursued on the same scale as in the 1980s, when the sheep population reached its maximum size of nearly 5 million animals. At the same time, goat raising was also thriving; however, it recorded a $39 \%$ fall in 2002 and the trend continues up to the present. The number of small ruminants in Poland amounts to 268,000 sheep and 117,500 goats. Mostly, goat husbandry is in small flocks of up to 4 animals, or 20 in the case of sheep (CSO 2010). The sheep and goats raised in Poland represent 30 and 10 breed types, respectively. The most common sheep breeds are Polish Heath (WRZOS), Pomeranian Coarsewool (POM), and Wielkopolska sheep (WLKP) because of their meat and wool quality. Three breeds constitute the largest goat population in Poland, i.e., Polish White Improved (BIALA USZL), Polish Color Improved (BARWNA USZL), and Saanen (SAAN).

The aim of this study was the identification and assessment of the prevalence of Cryptosporidium species in different breeds of sheep and goat in husbandry in Poland using molecular methods. In addition, the relationship between animal age, breed type, and the frequency of Cryptosporidium infections was determined.

\section{Materials and methods}

\section{Source of samples and study design}

During the three-year period 2011-2016, 234 lamb feces samples and 105 goat kids feces were collected from animals from birth up to the age of 9 weeks. The animals were housed in 61 sheep and 11 goat farms located in several administrative provinces of Poland where breeding of these animals is a tradition. The farms visited were operated according to a traditional grazing-based husbandry system. Farms and animals were randomly chosen for sampling. On the day of sampling, all animals were in good health without any visible symptoms of disease. All animals were periodically dewormed. The number of sampled animals per farm ranged from 3 to 4 in the case of lambs and from 5 to 10 for goat kids. The sampled lambs belonged to 16 breeds and their cross-breeds: Wielkopolska sheep (WLKP), Polish Mountain sheep (POG), Uhruska sheep (UHR), Kamieniecka sheep (KAM), Pomeranian Coarsewool (POM), Polish Heath (WRZOS), Blackhead Persian (CZGL), Polish Merino (MP), Olkuska Sheep (OLK), Suffolk (SUF), Bergschaf (BERG), Polish Lowland (PON), Whitehead Sheep (BOM), Żelazna Sheep (ŻEL), Podhale Sheep (CKP), and meat cross-breeds (MM).

The goat kids represented six breeds including meat crossbreeds (MK): Saanen (SAAN), Alpine (ALP), Polish White Improved (BIALA USZL), Polish Color Improved (BARWNA USZL), and Anglo-Nubian (ANGL-NUB). Upon collection, feces were placed into plastic containers, labeled, and sent to the laboratory. Before analysis, they were stored for a maximum of 1 week at $4{ }^{\circ} \mathrm{C}$, or at $-20{ }^{\circ} \mathrm{C}$, if processing was delayed more than 1 week.

\section{Molecular detection and species identification}

Parasite genomic DNA was extracted from $0.1 \mathrm{~g}$ of feces using a previously described method (Rzeżutka and Kaupke 2013). The correct performance of the method was monitored by a positive extraction control (feces of sheep contaminated with C. parvum oocysts (Iowa strain, Waterborne ${ }^{\mathrm{TM}}$, Inc., New Orleans, LA, USA)) and a negative control (water instead of the analyzed template). These controls were included for each set of analyzed samples and simultaneously processed. The nucleic acids were subjected to further purification with the use of a GeneMATRIX PCR/DNA Clean-Up Purification Kit, (EURx, Ltd., Gdańsk, Poland) as recommended by the manufacturer. The extracts containing parasite DNA were stored at $-20{ }^{\circ} \mathrm{C}$ until use.

The identification of Cryptosporidium species was performed at the $18 \mathrm{SSU}$ ribosomal RNA (rRNA) and COWP loci and was followed by subtyping at the GP60 gene locus (Homan et al. 1999; Xiao et al. 1999; Glaberman et al. 2002; Sulaiman et al. 2005). Subsequently, a restriction fragment 
length polymorphism (RFLP) analysis was performed for all positive 18 SSU rRNA and COWP PCR products. The analyses of 18 SSU rRNA amplicons were conducted using NdeI for initial identification and differentiation of C. parvum and $C$. hominis infections from other species infecting small ruminants and $X b a \mathrm{I}$ for differentiation of $C$. ubiquitum (lack of restriction site) from C. bovis and C. xiaoi (Xiao et al. 1999, 2006; Zintl et al. 2007). In addition, the COWP amplicons were subjected to $T a q$ I digestion for definitive confirmation of C. parvum or C. hominis presence (Homan et al. 1999). In addition to controls included during DNA isolation, the appropriate positive and negative controls were also included during PCR analyses.

Visualization of PCR amplicons and their restriction patterns was conducted in either 1.7 or $2.5 \%$ agarose gel stained with ethidium bromide. A definitive identification of Cryptosporidium species revealing the same "group"-specific restriction pattern (C. ubiquitum and $C$. bovis) was obtained on the basis of sequencing results. The 18 SSU rRNA amplicons were purified and sequenced, and their consensus sequences were compared with those available in the GenBank database as previously described (Rzeżutka and Kaupke 2013).

\section{Statistical analyses}

The relationship between the age of the lambs and goat kids and frequency of Cryptosporidium occurrence, and the dominance of infections caused by $C$. xiaoi, C. bovis, and C. ubiquitum in the tested sheep population were analyzed using one-way analysis of variance (ANOVA). A chi-square $\left(\chi^{2}\right)$ test was also used for showing the relationship between the occurrence of infection and animal age. A two-way analysis of variance without interactions with Tukey confidence intervals (CI) allowed demonstration of the differences in frequency of occurrence of particular parasite species in native Polish sheep breeds (POG, WLKP, KAM, WRZOS, MP, and UHR). Finally, the influence of sheep and goat breed on frequency of infections was investigated. All calculations were performed with a Statgraphics Centurion v. XV (Statpoint Technologies, Warrenton, USA).

\section{Results}

\section{Molecular identification of Cryptosporidium spp.}

The presence of Cryptosporidium DNA at the 18 SSU rRNA locus was detected in 45/234 (19.2\%) and in 39/105 (37.1\%) of lamb and goat feces, respectively. Successful amplification of the COWP gene fragment was obtained only for 2 samples, although previous 18 SSU rRNA PCR-RFLP analysis did not indicate the possible presence of $C$. parvum or $C$. hominis DNA. Subsequent GP60 subtyping revealed the presence of
IIaA17G1R1 C. parvum subtype in sheep and IIdA23G1 subtype in goat. Because of primer mismatches within the GP60 gene fragment, subtyping was unsuccessful for one C. parvum and one $C$. hominis strain. Despite multiple attempts, two C. parvum and $C$. hominis sheep isolates could not be successfully identified at the GP 60 locus, due to poor homology between forward and reverse primer sequences.

The RFLP and subsequent sequence analysis of all 18 SSU rRNA and COWP amplicons allowed identification in sheep of the following Cryptosporidium species: C. xiaoi $(n=33)$, C. bovis $(n=9), C$. ubiquitum $(n=3), C$. parvum $(n=2)$, C. hominis $(n=1)$, and Cryptosporidium spp. $(n=1)$. Goats were infected by $C$. xiaoi $(n=29)$ and $C$. parvum $(n=1)$. Animals were mostly infected by a single parasite species, except for three lambs in which mixed infections of two (C. xiaoi/C. parvum or C. xiaoi/Cryptosporidium spp.) or three (C. xiaoi/C. parvum/C. hominis) parasites were noticed. The representative 18 SSU rRNA nucleotide sequences of each species detected in sheep and goats from different age groups and breed types were deposited in GenBank under the accession numbers listed in Table 1.

\section{Distribution of Cryptosporidium spp. related to animal age and breed}

The infected lambs and goat kids were kept on $25(41 \%)$ and 7 (63.6\%) farms out of the 61 and 11 respectively investigated. C. xiaoi was found on $22(36 \%)$, C. bovis on $4(6.5 \%)$, C. ubiquitum on $3(4.9 \%)$, C. parvum on $2(3.2 \%)$, and C. hominis on $1(1.6 \%)$ sheep farm. On seven $(63.6 \%)$ out of 11 goat farms, C. xiaoi was detected, whereas C. parvum was only found on $1(9 \%)$ farm.

The analysis of variance showed that the frequency of infections did not differ significantly $(P=0.14, \alpha>0.05)$ between the tested age groups of lambs ( $<3$ and 3-9 weeks). The prevalence of the parasite among the youngest animals was $15.57 \%$ but was $23.21 \%$ in animals older than 3 weeks. However, the difference between these values was not statistically significant $\left(\mathrm{NIR}_{0.05}=10.16 \%\right)$. Also, there was no significant correlation observed between the presence of infection and animal age $\left(\chi^{2}=2.195, P=0.139>0.05\right)$. Neither were there any significant differences found in the frequency of infections in goats between the age groups $(P=0.06$, $\alpha>0.05$ ), with the infection prevalence within each group at 26.2 and $44.4 \%$. Infections caused by $C$. xiaoi were predominant without favoring any tested animal species. They were detected in 33 (14.1\%) of lambs and 29 (27.6\%) goat kids. C. xiaoi prevailed (82.1\%) in sheep, and the frequency of its occurrence was significantly higher $(F=26.99$, $P=0.000<0.05)$ than those of the infections caused by other parasite species such as $C$. bovis, $C$. ubiquitum, C. parvum, or C. hominis (Fig. 1). C. xiaoi was not only prevalent at herd level but also was the most often occurring parasite at farm 
Table 1 Prevalence of Cryptosporidium species in association to breed and age of tested animals

\begin{tabular}{|c|c|c|c|c|c|c|}
\hline \multirow{2}{*}{$\begin{array}{l}\text { Animal } \\
\text { species }\end{array}$} & \multirow[t]{2}{*}{ Breed } & \multirow{2}{*}{$\begin{array}{l}\text { Number of samples } \\
\text { (positive/tested) }\end{array}$} & \multicolumn{4}{|c|}{ Cryptosporidium infection in age groups } \\
\hline & & & 1 day-3 weeks & $\begin{array}{l}\text { GeneBank } \\
\text { accession no. }\end{array}$ & $>3-9$ weeks & $\begin{array}{l}\text { GeneBank } \\
\text { accession no. }\end{array}$ \\
\hline \multirow[t]{23}{*}{ Sheep } & \multirow[t]{4}{*}{ MP } & \multirow[t]{4}{*}{$10 / 39$} & C. xiaoi $\left(n=2^{\mathrm{a}, \mathrm{b}}\right)$ & \multirow[t]{2}{*}{ KY055383 } & $\begin{array}{l}\text { C. ubiquitum } \\
\quad(n=1)\end{array}$ & KY055388 \\
\hline & & & $\begin{array}{l}\text { Cryptosporidium } \\
\text { spp. }\left(n=1^{\mathrm{a}}\right)\end{array}$ & & C. xiaoi $(n=7)$ & $\begin{array}{l}\text { KY055389, } \\
\text { KY055396 }\end{array}$ \\
\hline & & & C. $\operatorname{parvum}\left(n=1^{\mathrm{b}}\right)$ & KY055411 & & \\
\hline & & & C. hominis $\left(n=1^{\mathrm{b}}\right)$ & KY055410 & & \\
\hline & POG & $4 / 31$ & C. xiaoi $(n=2)$ & KY055387 & C. xiaoi $(n=2)$ & KY055394 \\
\hline & \multirow[t]{3}{*}{ WLKP } & \multirow[t]{3}{*}{$12 / 24$} & C. bovis $(n=6)$ & $\begin{array}{l}\text { KY055380, } \\
\text { KY055381 }\end{array}$ & - & \\
\hline & & & C. xiaoi $\left(n=1^{\mathrm{c}}\right)$ & KY055382 & & \\
\hline & & & C. $\operatorname{parvum}\left(n=1^{\mathrm{c}}\right)$ & KY055409 & & \\
\hline & \multirow[t]{2}{*}{ UHR } & \multirow[t]{2}{*}{$4 / 24$} & \multirow[t]{2}{*}{ C. xiaoi $(n=1)$} & \multirow[t]{2}{*}{ KY055376 } & C. bovis $(n=1)$ & KY055378 \\
\hline & & & & & C. xiaoi $(n=2)$ & KY055377 \\
\hline & WRZOS & $7 / 24$ & $\begin{array}{l}\text { C. ubiquitum } \\
(n=1)\end{array}$ & KY055397 & C. xiaoi $(n=6)$ & $\begin{array}{l}\text { KY055385, } \\
\text { KY055386 }\end{array}$ \\
\hline & KAM & $2 / 23$ & C.xiaoi $(n=2)$ & $\begin{array}{l}\text { KY055384, } \\
\text { KY055390 }\end{array}$ & - & \\
\hline & OLK & $0 / 16$ & - & & - & \\
\hline & \multirow[t]{2}{*}{ MM } & \multirow[t]{2}{*}{$3 / 14$} & $\begin{array}{l}\text { C. ubiquitum } \\
(n=1)\end{array}$ & KY055391 & - & \\
\hline & & & C. xiaoi $(n=2)$ & KY055392 & & \\
\hline & CZGL & $2 / 11$ & C. xiaoi $(n=1)$ & KY055393 & C. bovis $(n=1)$ & KY055379 \\
\hline & PON & $1 / 8$ & - & & C. xiaoi $(n=1)$ & KY055395 \\
\hline & POM & $0 / 4$ & - & & - & \\
\hline & ZEL & $0 / 4$ & - & & - & \\
\hline & CKP & $0 / 3$ & - & & - & \\
\hline & SUF & $0 / 3$ & - & & - & \\
\hline & $\mathrm{BOM}$ & $0 / 2$ & - & & - & \\
\hline & BERG & $0 / 1$ & - & & - & \\
\hline \multirow[t]{7}{*}{ Goat } & SA & $12 / 25$ & C.xiaoi $(n=3)$ & KY055399 & C. xiaoi $(n=9)$ & KY055401 \\
\hline & $\mathrm{AL}$ & $11 / 18$ & - & & C. xiaoi $(n=11)$ & $\begin{array}{l}\text { KY055398, } \\
\text { KY055400, } \\
\text { KY055404 }\end{array}$ \\
\hline & BIALA USZL & $2 / 4$ & - & & C. xiaoi $(n=2)$ & KY055402 \\
\hline & $\begin{array}{l}\text { BARWNA } \\
\text { USZL }\end{array}$ & $3 / 20$ & C. xiaoi $(n=2)$ & KY055406 & C. xiaoi $(n=1)$ & KY055405 \\
\hline & $\mathrm{AN}$ & $7 / 8$ & C. xiaoi $(n=2)$ & KY055403 & C. xiaoi $(n=5)$ & KY055407 \\
\hline & \multirow[t]{2}{*}{$\mathrm{KB}$} & \multirow[t]{2}{*}{$4 / 30$} & C. $\operatorname{parvum}(n=1)$ & KY055412 & - & \\
\hline & & & C. xiaoi $(n=3)$ & KY055408 & - & \\
\hline
\end{tabular}

${ }^{\text {a }}$ Mixed infection C. xiaoi / Cryptosporidium spp. (not identified species)

${ }^{\mathrm{b}}$ Mixed infection C. xiaoi / C. parvum / C. hominis

${ }^{\mathrm{c}}$ Mixed infection C. xiaoi / C. parvum

level despite their dispersed locations. The least frequently detected species were $C$. parvum and $C$. hominis which were responsible for less than 3.1 and $1.7 \%$ of infections, respectively. There was no correlation observed between the frequency in occurrence of particular parasite species and breed in relation to native sheep breeds $(F=0.11 ; P=0.990>0.05)$. The frequency of Cryptosporidium occurrence in particular sheep breeds is presented in Fig. 2.

Cryptosporidium infections were most frequently observed in WLKP in comparison to KAM and POG $(F=3.23$, 


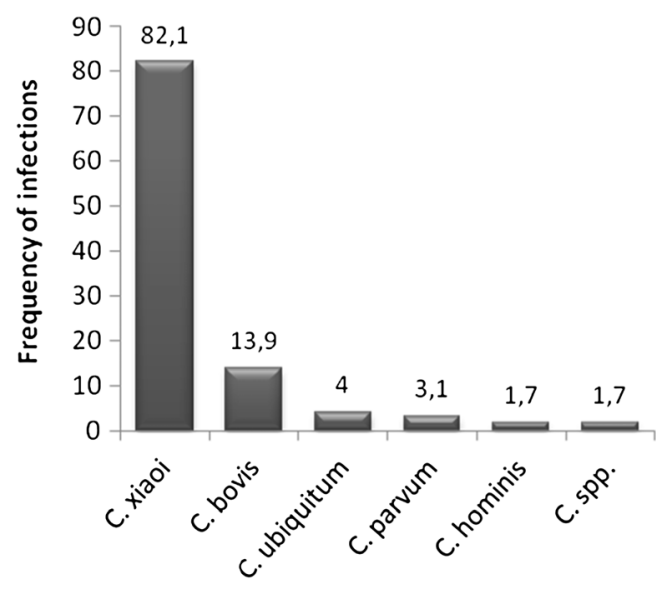

Fig. 1 The frequency of infections caused by particular Cryptosporidium species in the tested sheep population

$P=0.008<0.05)$. The frequencies of infections for other Polish breeds (UHR, MP, and WRZOS) did not differ significantly from each other. In the case of goats, more breed-related differences in parasite occurrence were found. Cryptosporidium was most frequently detected in ALP, ANGL-NUB, and SAAN than in animals of the BARWNA USZL and MK breeds $(F=6.57, P=0.001<0.05)$.

\section{Discussion}

Nowadays, molecular methods are widely used in diagnosis of Cryptosporidium infections in farm animals (Cacciò et al. 2013) including population and epidemiological studies (Geurden et al. 2008; Fiuza et al. 2011). So far, few studies aiming to identify and assess the parasite prevalence in small ruminants have been carried out in Europe and the majority of data come from France, Italy, England, and Romania (Misić et al. 2006; Mueller-Doblies et al. 2008; Quílez et al. 2008; Pritchard et al. 2008; Paoletti et al. 2009; Robertson et al.
2010; Díaz et al. 2010; Imre et al. 2013; Connelly et al. 2013; Cacciò et al. 2013; Rieux et al. 2013; Tzanidakis et al. 2014; Díaz et al. 2015). As seen in these studies, the worldwide prevalence of Cryptosporidium infections in sheep was in the range of 1.6 to $77.4 \%$ (Santín et al. 2007; Fiuza et al. 2011), while in goats, it was from 3.48 to $72.5 \%$ (Wang et al. 2014; Romero-Salas et al. 2016). This varied prevalence indicates a large geographical disparity in the frequency of infections that may be attributed to differences in animal age, breed, or the management and husbandry practices used (Mahfouz et al. 2014).

In this study, sheep and goats were carrying Cryptosporidium asymptomatically, with the extensiveness of invasion estimated at 19.2 and 37\%, respectively. Infections in sheep in Poland were diagnosed more often than in sheep flocks farmed in Belgium, Greece, or Norway (Geurden et al. 2008; Robertson et al. 2010; Tzanidakis et al. 2014). However, the parasite prevalence was lower than that observed in sheep from Serbia, Turkey, England, and Australia (Ryan et al. 2005; Misić et al. 2006; MuellerDoblies et al. 2008) and similar (17.45\%) to the prevalence in Italian flocks (Paoletti et al. 2009). In contrast to its incidence in the Polish sheep population, Cryptosporidium occurrence in goats was higher than that observed in other European countries (Misić et al. 2006; Geurden et al. 2008; Tzanidakis et al. 2014). Although the frequency of infections did not differ statistically between the studied age groups of lambs, the number of infected animals increased with their age. For example, in lambs aged up to 3 weeks, the prevalence was $15.6 \%$ and in older lambs, it was $23.2 \%$, while in goats, the prevalences were 26.2 and $44.4 \%$, respectively. A similar increase in Cryptosporidium prevalence related to animal age was also observed by Misić et al. (2006) and Rieux et al. (2013).

Among identified Cryptosporidium spp., C. xiaoi, C. parvum, C. ubiquitum, C. andersoni, C. hominis, C. bovis, C. ryanae, and C. scrofarum including the three genotypes rat, sheep I, and marsupial can infect small ruminants (Wang et al. 2010; Yang et al. 2014; Koinari et al. 2014; Li et al. 2016). Nevertheless, infections of sheep and goats are
Fig. 2 The frequency of infections caused by particular species of the parasite in relation to the tested sheep breeds

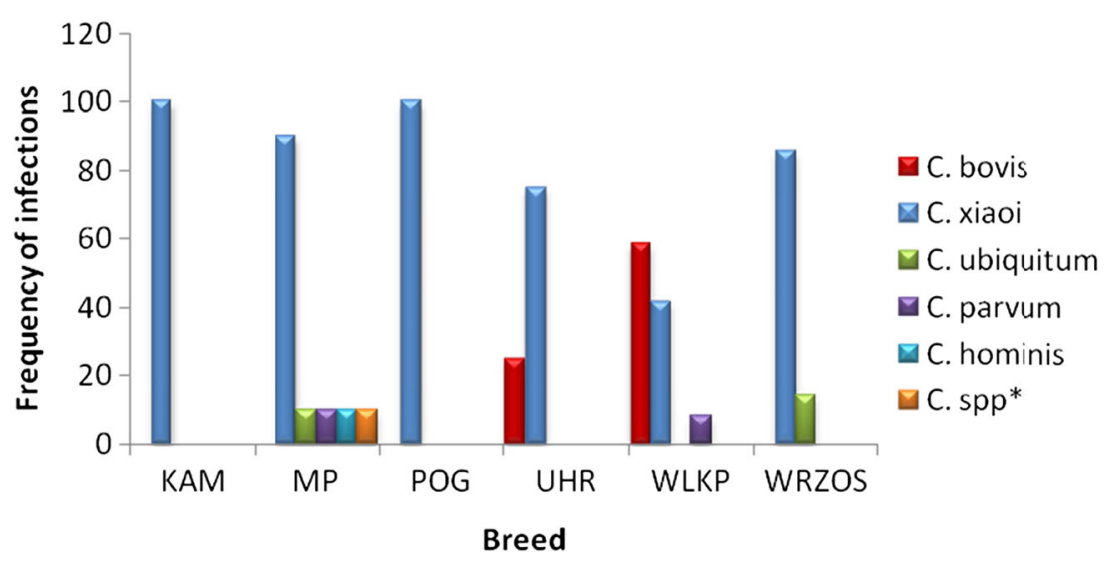


mainly caused by $C$. xiaoi, $C$. parvum, and C. ubiquitum (Geurden et al. 2008; Mueller-Doblies et al. 2008; Robertson et al. 2010; Yang et al. 2014; Mi et al. 2014; Paraud et al. 2014). These parasites were identified with different frequencies in sheep of different ages. Indeed, the most commonly Cryptosporidium detected in sheep in Europe was C. ubiquitum (Elwin and Chalmers 2008; Geurden et al. 2008; Robertson et al. 2010; Connelly et al. 2013; Tzanidakis et al. 2014), while in goats, the most evident numerically was C. parvum (Geurden et al. 2008; Tzanidakis et al. 2014), although their prevalence was not always the highest in the tested flock (Connelly et al. 2013; Tzanidakis et al. 2014). A similar distribution of C. ubiquitum has been found in sheep raised in North (Santín et al. 2007) and South America (Fiuza et al. 2011; Paze Silva et al. 2014) and Asia (Wang et al. 2010; Shen et al. 2011; Ye et al. 2013), but not in Australia, where C. xiaoi was the predominant species (Sweeny et al. 2011; Yang et al. 2014).

C. xiaoi infections prevailed in small ruminants in Poland, regardless of animal age, breed type (except WLKP), or farm location. This species was mostly identified in healthy animals (Rieux et al. 2013; Mahfouz et al. 2014) although its occurrence can also be associated with diarrhea in lambs and goat kids (Imre et al. 2013; Díaz et al. 2010; Díaz et al. 2015). Similar prevalence of the parasite was found in sheep in France (Rieux et al. 2013) and in goat flocks in Greece (Tzanidakis et al. 2014). Unlike other authors' observations, (Santín et al. 2007; Geurden et al. 2008; Wang et al. 2010), in this study, C. ubiquitum infections in lambs were characterized by low prevalence of $1.3 \%$. In contrast to sheep, C. ubiquitum was not identified in goats, although it has been previously detected in both newborn kids and adult goats (Tzanidakis et al. 2014; Mi et al. 2014; Wang et al. 2014). As demonstrated in previous studies, $C$. bovis has occasionally been identified in lambs (4.8\%) (Santín et al. 2007) and older animals up to the age of 2 years (1.1\%) (MuellerDoblies et al. 2008). A similar 5.5\% prevalence of C. bovis in lambs was also detected in Poland. Within Polish cattle herds, it was the most widely occurring species in young calves (Rzeżutka and Kaupke 2013). The high similarity (99.5\%) of sequences of the C. bovis strains derived from cattle and sheep raised in the same regions must signify the possibility of parasite exchange between ruminants and the importance of the environment in their transmission (data not shown).

Infections caused by $C$. parvum in sheep and goats can result in diarrhea (Quílez et al. 2008; Imre et al. 2013; Cacciò et al. 2013; Díaz et al. 2015) associated with a high occurrence of the parasite affecting up to $100 \%$ of individuals in the flock (Quílez et al. 2008). Nevertheless, when asymptomatic carriage of $C$. parvum has been reported, the extensiveness of invasion was low ( $0.73 \%$ in sheep) (Geurden et al. 2008 ) or moderate $(20.3 \%$ in goats) (Mi et al. 2014). The differences observed in the course of infection could be attributed to different pathogenicity of $C$. parvum strains. In this study, C. parvum was detected in $0.85 \%$ in sheep and $0.95 \%$ in goats aged up to 3 weeks. The low age of asymptomatically infected animals is consistent with the observations of Ryan et al. (2005) and Santín et al. (2007). Surprisingly, in a previous study carried out in Poland, $10.1 \%$ prevalence of C. parvum in lambs older than 3 months was observed in sheep flocks in the Wielkopolska region (Majewska et al. 2000). Unlike our results, in that study, other parasite species commonly occurring in small ruminants were not identified, probably due to limitations of the methods used.

Cryptosporidiosis does not constitute a major health problem in sheep and goats. However, infected animals can be reservoirs of zoonotic Cryptosporidium species for humans (Lange et al. 2014). C. parvum, C. hominis, C. ubiquitum, and $C$. andersoni infections in ruminants are of particular importance, due to the zoonotic nature of these parasites (Hijjawi et al. 2010; Cieloszyk et al. 2012; Cacciò et al. 2013; Jiang et al. 2014). Among several C. parvum genetic families, strains belonging to the IIa and IId families cause disease in humans and animals (Xiao and Ryan 2004; Abe et al. 2006; Plutzer and Karanis 2009). In this study, the presence of the IIaA17G1R1 subtype in lambs and IIdA23G1 in goat kids was demonstrated. Apart from sheep, IIaA17G1R1 has previously been detected in cattle in Poland and other countries in Europe (Stantic-Pavlinic et al. 2003; Wielinga et al. 2008; Plutzer and Karanis 2007; Brook et al. 2009; Imre et al. 2013; Kaupke and Rzeżutka 2015). This strain was among two other subtypes (IIaA15G2R1 and IIaA16G1R1b) mostly infecting cattle in Poland (Kaupke and Rzeżutka 2015). A common subtype occurrence in both cattle and sheep indicates the possibility of parasite transmission between different species of ruminants kept in the same area. In addition, the importance of the IIaA17G1R1 C. parvum subtype in the epidemiology of human cryptosporidiosis has previously been shown (Soba and Logar 2008; Sharbatkhori et al. 2015). For the first time, the IIdA23G1 subtype was detected in a goat host. However, it has been reported in cattle herds in Sweden, Spain, and Poland (Silverlås et al. 2010; Quílez et al. 2011; Kaupke and Rzeżutka 2015). C. hominis infections in small ruminants are rare (Connelly et al. 2013; Koinari et al. 2014), and this observation has also been confirmed by our finding of C. hominis DNA in a single stool sample originating from a 3-week-old lamb. In sheep, there were also mixed infections detected caused by two (C. xiaoi/C. parvum, C. ubiquituum/C. parvum, C. ubiquituum/C. bovis) or three (C. xiaoi/C. parvum/ C. hominis) Cryptosporidium species. In fact, mixed infections were only sporadically observed in sheep (Elwin and Chalmers 2008; Sweeny et al. 2011; Yang et al. 2014).

There is a lack of studies aiming to assess the relationship between the animal breed, occurrence of Cryptosporidium 
species, and the frequency of infections. In the current study, a more pervasive invasion was found in sheep of WLKP and MP breeds as well as in goats of AL breed. Likewise, the virulence of Cryptosporidium strains detected in sheep and goats appear to be of less importance due to the asymptomatic course of infections caused by them. The results may indicate the differences in sensitivity of individual sheep and goat breeds to Cryptosporidium infection. Contrary to this observation, Romero-Salas et al. (2016) suggested that the breed, age, or gender of animals have no significant impact on Cryptosporidium prevalence in small ruminants. Nevertheless, the sampled animals represented two goat (Mixed and Nubian) and three sheep breed types (Pelibuey, Dorper, and Kathadin) not raised in Europe, which to some extent could explain the observed differences. Nevertheless, different resistance of sheep to gastrointestinal nematode parasites in various breeding conditions and environments has been reported by Bouix et al. (1998). The goat breed was not indicated as a significant risk factor for Cryptosporidium infection in dairy goat farms in Western France (Delafosse et al. 2006).

Nowadays, sheep and goat breeding in Poland is not as popular as it was in the last century. The size of flocks is small, often comprising two or three animals (CSO 2010). Although the studies were conducted on randomly selected animals originating from different farms and locations, the number of tested animals did not reflect the size of the small ruminant population in the country. This could be taken as a major limitation in interpretation of the results on the occurrence of Cryptosporidium infections in sheep and goat herds in Poland. The results on the occurrence of Cryptosporidium species in the investigated sheep and goat breeds should also be interpreted with caution because the higher prevalence of a particular parasite species in the flock does not necessarily indicate the greater sensitivity of the animal breed to Cryptosporidium infection. It could be a result of an endemic occurrence of the parasite in this area. Certainly, if a higher number of animals representing particular breed type were tested, then data regarding the host-parasite interactions would be more evident.

\section{Conclusions}

Cryptosporidium infections are widespread in lambs in spite of the age of animals, breed type, and farm location. The occurrence of $C$. parvum and $C$. hominis in small ruminants highlights the importance of these animal species in parasite circulation between animal and human hosts. However, the epidemiology of infections and the occurrence of other zoonotic species in small ruminants, with their attendant public health significance, require further studies.
Acknowledgements The study was supported by the Ministry of Science and Higher Education of Poland (Research project no. S/163). The authors would like to thank Dr. Rachel M. Chalmers of the Cryptosporidium Reference Unit in Swansea, UK for providing Cryptosporidium hominis DNA; the Polish Association of Ovine and Caprine Breeders; as well as individual farmers for the participation in this study.

Open Access This article is distributed under the terms of the Creative Commons Attribution 4.0 International License (http:// creativecommons.org/licenses/by/4.0/), which permits unrestricted use, distribution, and reproduction in any medium, provided you give appropriate credit to the original author(s) and the source, provide a link to the Creative Commons license, and indicate if changes were made.

\section{References}

Abe N, Matsubayashi M, Kimata I, Iseki M (2006) Subgenotype analysis of Cryptosporidium parvum isolates from humans and animals in Japan using the $60-\mathrm{kDa}$ glycoprotein gene sequences. Parasitol Res 99:303-305

Balicka-Ramisz A, Ramisz S, Snitynskyj V (2012) Prevalence of coccidia infection in goats in Western Pomerania (Poland) and West Ukraine region. Ann Parasitol 58:167-171

Bouix J, Krupinski J, Rzepecki R, Nowosad B, Skrzyzala I, Roborzynski M, Fudalewicz-Niemczyk W, Skalska M, Malczewski A, Gruner L (1998) Genetic resistance to gastrointestinal nematode parasites in Polish long-wool sheep. Int J Parasitol 11:1797-1804

Brook EJ, Anthony Hart C, French NP, Christley RM (2009) Molecular epidemiology of Cryptosporidium subtypes in cattle in England. Vet J 179:378-382

Buddle BM, Herceg M, Ralston MJ, Pulford HD, Millar KR, Elliott DC (1988) A goat mortality study in the southern North Island. N Z Vet J 36:167-170

Cacciò SM, Sannella AR, Mariano V, Valentini S, Berti F, Tosini F, Pozio E (2013) A rare Cryptosporidium parvum genotype associated with infection of lambs and zoonotic transmission in Italy. Vet Parasitol 191:128-131

Cieloszyk J, Goñi P, García A, Remacha MA, Sánchez E, Clavel A (2012) Two cases of zoonotic cryptosporidiosis in Spain by the unusual species Cryptosporidium ubiquitum and Cryptosporidium felis. Enferm Infecc Microbiol Clin 30:549-551

Connelly L, Craig BH, Jones B, Alexander CL (2013) Genetic diversity of Cryptosporidium spp. within a remote population of soay sheep on St. Kilda Islands, Scotland. Appl Environ Microbiol 79:22402246

CSO (2010) Working Group of National Agricultural Census of 2010. Livestock and selected elements of animal production methods. Zakład Wydawnictw Statystycznych, Warszawa

Delafosse A, Castro-Hermida JA, Baudry C, Ares-Mazás E, Chartier C (2006) Herd-level risk factors for Cryptosporidium infection in dairy-goat kids in western France. Prev Vet Med 77:109-121

Díaz P, Quílez J, Prieto A, Navarro E, Pérez-Creo A, Fernández G, Panadero R, López C, Díez-Baños P, Morrondo P (2015) Cryptosporidium species and subtype analysis in diarrhoeic preweaned lambs and goat kids from north-western Spain. Parasitol Res 114:4099-4105

Díaz P, Quílez J, Robinson G, Chalmers RM, Díez-Baños P, Morrondo P (2010) Identification of Cryptosporidium xiaoi in diarrhoeic goat kids (Capra hircus) in Spain. Vet Parasitol 172:132-134

Elwin K, Chalmers RM (2008) Contemporary identification of previously reported novel Cryptosporidium isolates reveals Cryptosporidium 
bovis and the cervine genotype in sheep (Ovis aries). Parasitol Res 102:1103-1105

Fiuza VR, Cosendey RI, Frazão-Teixeira E, Santín M, Fayer R, de Oliveira FC (2011) Molecular characterization of Cryptosporidium in Brazilian sheep. Vet Parasitol 175:360-362

Geurden T, Thomas P, Casaert S, Vercruysse J, Claerebout E (2008) Prevalence and molecular characterisation of Cryptosporidium and Giardia in lambs and goat kids in Belgium. Vet Parasitol 155:142-145

Glaberman S, Moore JE, Lowery CJ, Chalmers RM, Sulaiman I, Elwin K, Rooney PJ, Millar BC, Dooley JS, Lal AA, Xiao L (2002) Three drinking-water-associated cryptosporidiosis outbreaks, Northern Ireland. Emerg Infect Dis 8:631-633

Giles M, Chalmers R, Pritchard G, Elwin K, Mueller-Doblies D, CliftonHadley F (2009) Cryptosporidium hominis in a goat and a sheep in the UK. Vet Rec 164:24-25

Hijjawi N, Ng J, Yang R, Atoum MF, Ryan U (2010) Identification of rare and novel Cryptosporidium GP60 subtypes in human isolates from Jordan. Exp Parasitol 125:161-164

Homan W, van Gorkom T, Kan YY, Hepener J (1999) Characterization of Cryptosporidium parvum in human and animal feces by single-tube nested polymerase chain reaction and restriction analysis. Parasitol Res 85:707-712

Imre K, Luca C, Costache M, Sala C, Morar A, Morariu S, Ilie MS, Imre M, Dărăbuş G (2013) Zoonotic Cryptosporidium parvum in Romanian newborn lambs (Ovis aries). Vet Parasitol 191:119-122

Jiang Y, Ren J, Yuan Z, Liu A, Zhao H, Liu H, Chu L, Pan W, Cao J, Lin Y, Shen Y (2014) Cryptosporidium andersoni as a novel predominant Cryptosporidium species in outpatients with diarrhoea in Jiangsu Province, China. BMC Infect Dis 14:555

Kaupke A, Rzeżutka A (2015) Emergence of novel subtypes of Cryptosporidium parvum in calves in Poland. Parasitol Res 114: 4709-4716

Kang'ethe EK, Mulinge EK, Skilton RA, Njahira M, Monda JG, Nyongesa C, Mbae CK, Kamwati SK (2012) Cryptosporidium species detected in calves and cattle in Dagoretti, Nairobi, Kenya. Trop Anim Health Prod 44(Suppl 1):S25-S31

Karanis P, Plutzer J, Halim NA, Igori K, Nagasawa H, Ongerth J, Liqing M (2007) Molecular characterization of Cryptosporidium from animal sources in Qinghai province of China. Parasitol Res 101:1575-1580

Koinari M, Lymbery AJ, Ryan UM (2014) Cryptosporidium species in sheep and goats from Papua New Guinea. Exp Parasitol 141:134-137

Lange H, Johansen OH, Vold L, Robertson LJ, Anthonisen IL, Nygard K (2014) Second outbreak of infection with a rare Cryptosporidium parvum genotype in schoolchildren associated with contact with lambs/goat kids at a holiday farm in Norway. Epidemiol Infect 142:2105-2113

Li P, Cai J, Cai M, Wu W, Li C, Lei M, Xu H, Feng L, Ma J, Feng Y, Xiao L (2016) Distribution of Cryptosporidium species in Tibetan sheep and yaks in Qinghai, China. Vet Parasitol 215:58-62

Mahfouz ME, Mira N, Amer S (2014) Prevalence and genotyping of Cryptosporidium spp. in farm animals in Egypt. J Vet Med Sci 76: $1569-1575$

Majewska AC, Werner A, Sulima P, Luty T (2000) Prevalence of Cryptosporidium in sheep and goats bred on five farms in westcentral region of Poland. Vet Parasitol 89:269-275

Malczewski A (1970) Gastro-intestinal helminths of ruminants in Poland. I. Helminth fauna of sheep. Acta Parasit Pol 18:245-254

Mason RW, Hartley WJ, Tilt L (1981) Intestinal cryptosporidiosis in a kid goat. Aust Vet J 57:386-388

Mi R, Wang X, Huang Y, Zhou P, Liu Y, Chen Y, Chen J, Zhu W, Chen Z (2014) Prevalence and molecular characterization of Cryptosporidium in goats across four provincial level areas in China. PLoS One 9(10): e111164

Misić Z, Katic-Radivojevic S, Kulisic Z (2006) Cryptosporidium infection in lambs and goat kids in Serbia. Acta Vet (Beogr) 56:49-54
Mueller-Doblies D, Giles M, Elwin K, Smith RP, Clifton-Hadley FA, Chalmers RM (2008) Distribution of Cryptosporidium species in sheep in the UK. Vet Parasitol 154:214-219

Ozmen O, Yukari BA, Haligur M, Sahinduran S (2006) Observations and immunohistochemical detection of Coronavirus, Cryptosporidium parvum and Giardia intestinalis in neonatal diarrhoea in lambs and kids. Schweizer Archiv fur Tierheilkunde 148:357-364

Paoletti B, Giangaspero A, Gatti A, Iorio R, Cembalo D, Milillo P, Traversa D (2009) Immunoenzymatic analysis and genetic detection of Cryptosporidium parvum in lambs from Italy. Exp Parasitol 122: 349-352

Paraud C, Pors I, Rieux A, Brunet S (2014) High excretion of Cryptosporidium ubiquitum by peri-parturient goats in one flock in western France. Vet Parasitol 202:301-304

Paz e Silva FM, Lopes RS, Bresciani KD, Amarante AF, Araujo JP (2014) High occurrence of Cryptosporidium ubiquitum and Giardia duodenalis genotype E in sheep from Brazil. Acta Parasitol 59:193-196

Plutzer J, Karanis P (2009) Genetic polymorphism in Cryptosporidium species: an update. Vet Parasitol 165:187-199

Plutzer J, Karanis P (2007) Genotype and subtype analyses of Cryptosporidium isolates from cattle in Hungary. Vet Parasitol 146:357-362

Pritchard GC, Marshall JA, Giles M, Mueller-Doblies D, Sayers AR, Marshall RN, Elwin K, Chalmers RM (2008) Cryptosporidium species in lambs submitted for diagnostic postmortem examination in England and Wales. Vet Rec 163:688-689

Quílez J, Torres E, Chalmers RM, Hadfield SJ, Del Cacho E, SánchezAcedo C (2008) Cryptosporidium genotypes and subtypes in lambs and goat kids in Spain. Appl Environ Microbiol 74:6026-6031

Quílez J, Vergara-Castiblanco C, Monteagudo L, Del Cacho E, SánchezAcedo C (2011) Multilocus fragment typing and genetic structure of Cryptosporidium parvum isolates from diarrheic preweaned calves in Spain. Appl Environ Microbiol 77:7779-7786

Rieux A, Paraud C, Pors I, Chartier C (2013) Molecular characterization of Cryptosporidium spp. in pre-weaned kids in a dairy goat farm in western France. Vet Parasitol 192:268-272

Robertson LJ (2009) Giardia and Cryptosporidium infections in sheep and goats: a review of the potential for transmission to humans via environmental contamination. Epidemiol Infect 137:913-921

Robertson LJ, Gjerde BK, Furuseth Hansen E (2010) The zoonotic potential of Giardia and Cryptosporidium in Norwegian sheep: a longitudinal investigation of 6 flocks of lambs. Vet Parasitol 171:140-145

Romero-Salas D, Alvarado-Esquivel C, Cruz-Romero A, AguilarDomínguez M, Ibarra-Priego N, Merino-Charrez JO, Pérez de León AA, Hernández-Tinoco J (2016) Prevalence of Cryptosporidium in small ruminants from Veracruz, Mexico. BMC Vet Res 19:12-14

Ryan UM, Bath C, Robertson I, Read C, Elliot A, McInnes L, Traub R, Besier B (2005) Sheep may not be an important zoonotic reservoir for Cryptosporidium and Giardia parasites. Appl Environ Microbiol 71:4992-4997

Rzeżutka A, Kaupke A (2013) Occurrence and molecular identification of Cryptosporidium species isolated from cattle in Poland. Vet Parasitol 196:301-306

Santín M, Trou JM, Fayer R (2007) Prevalence and molecular characterization of Cryptosporidium and Giardia species and genotypes in sheep in Maryland. Vet Parasitol 146:17-24

Sharbatkhori M, Nazemalhosseini Mojarad E, Taghipour N, Pagheh AS, Mesgarian F (2015) Prevalence and genetic characterization of Cryptosporidium spp. in diarrheic children from Gonbad Kavoos City, Iran. Iran J Parasitol 10:441-447

Shen Y, Yin J, Yuan Z, Lu W, Xu Y, Xiao L, Cao J (2011) The identification of the Cryptosporidium ubiquitum in pre-weaned Ovines from Aba Tibetan and Qiang autonomous prefecture in China. Biomed Environ Sci 24:315-320 
Silverlås C, Näslund K, Björkman C, Mattsson JG (2010) Molecular characterisation of Cryptosporidium isolates from Swedish dairy cattle in relation to age, diarrhoea and region. Vet Parasitol 169:289-295

Soba B, Logar J (2008) Genetic classification of Cryptosporidium isolates from humans and calves in Slovenia. Parasitology 135:1263-1270

Sulaiman IM, Hira PR, Zhou L, Al-Ali FM, Al-Shelahi FA, Shweiki HM, Iqbal J, Khalid N, Xiao L (2005) Unique endemicity of cryptosporidiosis in children in Kuwait. J Clinical Microbiol 43:2805-2809

Stantic-Pavlinic M, Xiao L, Glaberman S, Lal AA, Orazen T, RatajVerglez A, Logar J, Berce I (2003) Cryptosporidiosis associated with animal contacts. Wien Klin Wochenschr 115:125-127

Sweeny JP, Ryan UM, Robertson ID, Yang R, Bell K, Jacobson C (2011) Longitudinal investigation of protozoan parasites in meat lamb farms in southern Western Australia. Prev Vet Med 101:192-203

Taylan-Ozkan A, Yasa-Duru S, Usluca S, Lysen C, Ye J, Roellig DM, Feng Y, Xiao L (2016) Cryptosporidium species and Cryptosporidium parvum subtypes in dairy calves and goat kids reared under traditional farming systems in Turkey. Exp Parasitol 170:16-20

Tzanidakis N, Sotiraki S, Claerebout E, Ehsan A, Voutzourakis N, Kostopoulou D, Stijn C, Vercruysse J, Geurden T (2014) Occurrence and molecular characterization of Giardia duodenalis and Cryptosporidium spp. in sheep and goats reared under dairy husbandry systems in Greece. Parasite 21:45

Vasilkova Z, Krupicer I, Legath J, Kovalkovicova N, Pet'ko B (2004) Coccidiosis of small ruminants in various regions of Slovakia. Acta Parasitol 49:272-275

Wang Y, Feng Y, Cui B, Jian F, Ning C, Wang R, Zhang L, Xiao L (2010) Cervine genotype is the major Cryptosporidium genotype in sheep in China. Parasitol Res 106:341-347
Wang R, Li G, Cui B, Huang J, Cui Z, Zhang S, Dong H, Yue D, Zhang L, Ning C, Wang M (2014) Prevalence, molecular characterization and zoonotic potential of Cryptosporidium spp. in goats in Henan and Chongqing, China. Exp Parasitol 142:11-16

Wielinga PR, de Vries A, van der Goot TH, Mank T, Mars MH, Kortbeek LM, van der Giessen JW (2008) Molecular epidemiology of Cryptosporidium in humans and cattle in the Netherlands. Int $\mathbf{J}$ Parasitol 38:809-817

Xiao L (2010) Molecular epidemiology of cryptosporidiosis: an update. Exp Parasitol 124:80-89

Xiao L, Escalante L, Yang C, Sulaiman I, Escalante AA, Montali RJ, Fayer R, Lal AA (1999) Phylogenetic analysis of Cryptosporidium parasites based on the small-subunit rRNA gene locus. Appl Environ Microbiol 65:1578-1583

Xiao L, Moore JE, Ukoh U, Gatei W, Lowery CJ, Murphy TM, Dooley JS, Millar BC, Rooney PJ, Rao JR (2006) Prevalence and identity of Cryptosporidium spp. in pig slurry. Appl Environ Microbiol 72:44614463

Xiao L, Ryan UM (2004) Cryptosporidiosis: an update in molecular epidemiology. Curr Opin Infect Dis 17:483-490

Yang R, Jacobson C, Gardner G, Carmichael I, Campbell AJ, Ryan U (2014) Longitudinal prevalence, oocyst shedding and molecular characterisation of Cryptosporidium species in sheep across four states in Australia. Exp Parasitol 145:14-21

Ye J, Xiao L, Wang Y, Wang L, Amer S, Roellig DM, Guo Y, Feng Y (2013) Periparturient transmission of Cryptosporidium xiaoi from ewes to lambs. Vet Parasitol 197:627-633

Zintl A, Neville D, Maguire D, Fanning S, Mulcahy G, Smith HV, De Waal T (2007) Prevalence of Cryptosporidium species in intensively farmed pigs in Ireland. Parasitol 134:1575-1582 